\title{
Microbond fibre bundle pullout technique to evaluate the interfacial adhesion of polyethylene and polypropylene self reinforced composites
}

\author{
M. Sharan Chandran ${ }^{1}$ and K. Padmanabhan ${ }^{2^{*}}$
}

\section{*Correspondence:}

padmanabhan.k@vit.ac.in

2 Department

of Manufacturing

Engineering, School

of Mechanical Engineering,

Vellore Institute

of Technology University,

Vellore, Tamil Nadu 632014,

India

Full list of author information

is available at the end of the article

\begin{abstract}
Self reinforced polymer composites possess a comparable shear and tensile strength unlike the glass or carbon fibre reinforced composites. Important deciding factors of overall efficiency of composite materials are the interfacial adhesion properties between the fibre and the matrix. Structural properties and processability of composite materials are also dependent on adhesion between the fibre and the matrix. Polypropylene and polyethylene self-reinforced composites are the systems investigated here for the purpose of analyzing the interfacial properties of these systems. Multiple fibre pullout test is an alternate method for single fibre pullout test with added advantages of more reliable statistically averaged data with less standard deviation and minimized chances for fibre breakage during testing. This test can also be verified for various volume fractions unlike single fibre pullout test. Micro bonds of matrix materials are cured on a bundle of fibres and by using a micro vise as an additional fixture, the interfacial strength and other interfacial properties are evaluated through fibre pullout. Surface tension between the fibre and the matrix plays an important role in this test. Thus from the contact angle and the frictional properties of the interface, the interface properties are evaluated. Interface properties obtained from this meso-mechanical semi empirical method are also compared with the properties evaluated from micromechanical formulations. Spectroscopic studies revealed the bonding characteristics during the interface formation and after failure. Fractography reveals the cause and nature of failure and substantiate the analysis.
\end{abstract}

Keywords: Single polymer composites, Interface analysis, Fractography, SEM, FTIR, Drop mass impact

\section{Introduction}

Interfacial adhesion properties of fibre and the matrix play an important role in overall performance of the composite materials [1,2]. Chemical composition and the fibre surface characteristics are the major parameters that determine the interfacial strength of fibre and matrix [3]. There are various methods developed to evaluate the interfacial properties like pull-out test, fragmentation test, push-out test, microbond test etc. [4-6]. Pull-out and microbond test are more adopted among them because of high 
reproducibility and simplicity in conducting experiments [7, 8]. Stress based (by evaluating interfacial shear strength, IFSS) and energy based fracture mechanics approaches (by evaluating energy release rate) are developed in order to analyze the interface properties with these methods. All of these methods satisfactorily explain the interface de-bonding phenomenon $[8,9]$. Unlike the previous methods, in recent literature an alternative method of determining the local interfacial shear strength proposes that the crack initiation force is not necessary to determine the IFSS [10]. Maximum force attained and post de-bonding force is used to determine IFSS in this study. Different numerical models and experimental methods are proposed by various researchers to study the interface properties so far [11-13]. The composites with their matrix and the reinforcement composed of the same family of materials but different in properties and processing parameters are known as the self reinforced polymer composite (SRPC) systems. The SRPC concept was first described by Capiati and Porter in 1975, in which single polymer composites fabricated from polyethylene (PE) powder and polyethylene (PE) filaments of different melting points were observed to be superior in interfacial shear strength by a pull-out method [13].

Various attempts to improve the interface adhesion have been reported recently. Zhi et al. compared the interfacial shear strength (IFSS) and other interface properties of fibre micro-balloon epoxy ternary composites obtained through experimental method of microbond test with that of numerical analysis using ANSYS software. They reported that the fibre diameter, volume fraction and size of the micro-balloon particle have substantial influence on IFSS [14]. Ma et al. [15] reported that the IFSS evaluated through microbond test of graphene oxide grafted carbon fibre improves IFSS considerably. In a hygrothermal ageing study conducted by Wang et al. [16] on carbon fibre reinforced polymer, hygrothermal ageing degradation of interface adhesion was found to be reducing under a combination of electrochemical oxidation and sizing treatments. Minty et al. [17] discussed the correlation of IFSS and the matrix properties like glass transition temperature, storage modulus and linear coefficient of thermal expansion. In an assessment of interfacial properties at the yarn scale on flax/epoxy and flax/vinyl ester composites, Seghini et al. [18] reported that under fibre fragmentation test, flax/epoxy system had possessed the lowest values of critical fragmentation length and interfacial debonding length and highest values of IFSS. Fu et al. [19] successfully enhanced the interfacial properties of carbon fibre reinforced epoxy composites without sacrificing fibre strength by a layer-by-layer self-depositing method of graphene oxide/silica multilayer films on carbon fibre surface. Requile et al. [20] investigated the hygro-mechanical behavior of single hemp fibre/epoxy interface by microdroplet debonding test.

Polyester and polyolefin materials are the most studied polymers, and the most frequently used processing method is film stacking. Generally, matrix film is selected which has lower melting point than the fibers, so that only the matrix films melt under thermal processing keeping the fibre intact. Polypropylene (PP) and polyethylene (PE) are thermoplastic polymers with a wide range of melting temperature. This is depending on the stereochemistry in PP crystallinity and molecular weight in PE. In self reinforced composites, PP or PE fibres with a higher melting point is reinforced with the same family of polymer matrix but with lower melting point by a heat treatment process just below the softening temperature so that the matrix softens and adheres to the fabric keeping 
the fibre intact. Interesting applications of SRPCs are in ultra-light structures, air, sea and land cargo containers, transport, and electronic packaging due to their high specific properties. Due to their comparable shear and tensile properties, they possess better interfacial strength too [21]. Relevance of interfacial properties in adhesion of matrix and reinforcement is emphasizing the need to study these properties in details. Even though there is no standard test method exists, many test methods are developed by various researchers so far [22-26]. A microbundle pullout test was developed by Sastry and co-workers in 1993 with single fibre pulled out from epoxy matrix [23]. Due to the highly scattered test results in all the experimental methods of interfacial studies, it is proposed to test dozens of samples to obtain a statistically significant average value for interfacial bond strength. The present work was developed by Padmanabhan [24-26] and verified in different systems. Though the underlying physical principles are same as the single fibre bundle test, modified methodology with refined test parameters resulted in more sophisticated and reliable tool for evaluation of interfacial properties. This work concentrates on evaluation of interfacial properties of self reinforced composites (SRCs) by micro-mechanical and meso-mechanical approaches and analyzing the feasibility of this test method in polyolefin based SRC systems. The work also focuses on spectroscopic and fractographic methods to analyze the interfacial properties. Figure 1 is the schematic representation of the test and Fig. 2 represents the optical micrograph of the prepared samples.

\section{Theoretical considerations}

\section{Micromechanical approach}

Interfacial shear strength parameters can be evaluated by micromechanical formulations of Chamis and Rosen with various testing parameters and with the help of CADEC software [27]. Interfacial shear strength obtained by micro-bond multiple fibre pullout tests is compared with micromechanical predictions. Though these formulations do not include any adhesion related parameters, it is required to compare the results in order

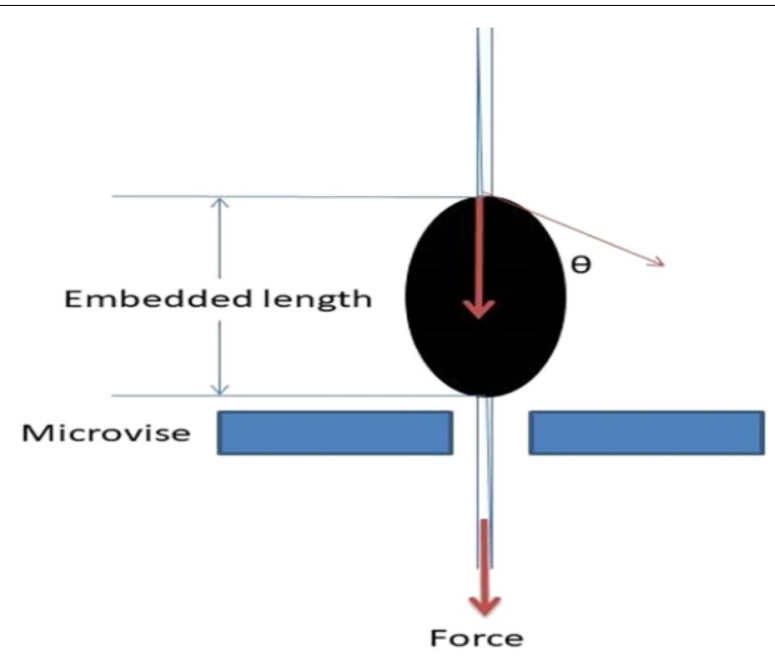

Fig. 1 Schematic diagram of microbond bundle pullout test 


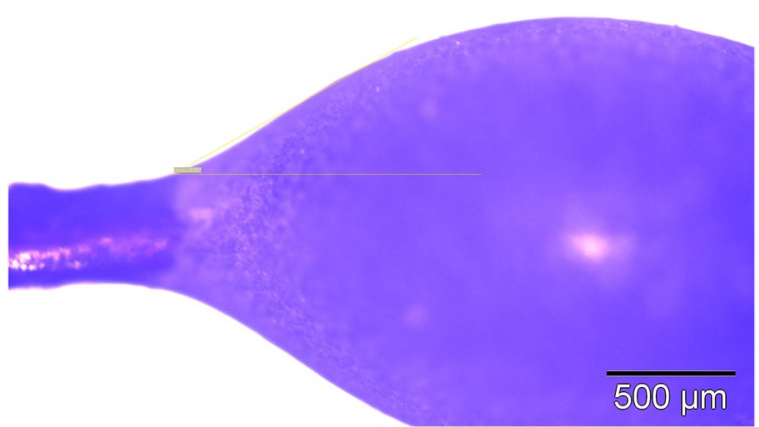

Fig. 2 Blob around the fibre bundle

to emphasize the importance and validity of meso-mechanical approach of micro-bond multiple pullout technique.

Two different sets of fibre bundles are tested by pullout tests. By considering the volume fraction in various cases in-plane shear strength can be calculated based on Chamis and Rosen's models [27]. In-plane shear strength can be calculated by using Chamis prediction as

$$
F=\tau_{m u} C_{v}\left[1+\left(\mathrm{V}_{\mathrm{f}}-\sqrt{\mathrm{V}_{\mathrm{f}}}\right)\left(1-\mathrm{G}_{\mathrm{m}} / \mathrm{G}_{\mathrm{f}}\right)\right]
$$

$\tau_{m u}$ is the matrix strength, $V_{f}$, is the fibre volume fraction, and $G_{m}$ and $G_{f}$ are the matrix and fibre shear modulus respectively. $\mathrm{C}_{\mathrm{v}}$ is a factor representing the voids in the system. According to Rosen's prediction, shear strength is modified by introducing composite shear modulus and the shear strain and the formulation is

$$
\tau_{\text {comp }}=\mathrm{F} \tanh \left(\gamma \mathrm{G}_{12} / \mathrm{F}\right)
$$

$\mathrm{G}_{12}$ is the composite shear modulus, $\gamma$, is the shear strain at failure.

\section{Micro-bond bundle pull-out test}

The method discussed here is a less clumsy method compared to all other methods like single fibre pull-out test or fibre slab/resin pull-out method developed for interfacial analysis. Bundle pull-out test has more physical relevance and provides well averaged and more accurate results.

CAM model or the cylindrical assemblage of fibres is considered in the analysis. Limited drop size and contact angle can only be used in this analysis and proper care should be taken in preparing and selecting the samples. The laminates are usually prepared by hot compaction process but the effect of pressure is not incorporated in this test method. These conservative results may be slightly varied from the actual results due to these reasons. Interfacial intrinsic bond strength $(\tau)$ is given by the peak debonding force divided by the available outer interfacial area due to the stress distribution from the fibres to the matrix and if the matrix is considerably weaker than the fibre [28].

$$
\tau=P / \pi \varphi l
$$

where, $P$ is the peak debonding force minus the initial frictional force, if any, $\varphi$ is the average diameter of the fiber bundle and $l$ is the length of the resin droplet in the fiber 
bundle. Microvise is an optimally designed device which does not produce any frictional force with the fibre or the resin. The area selected in the above equation is based on the assumption that the failure actually occurs through the fibre matrix interface which can be confirmed by keeping the drop size small. Higher drop size causes more matrix region supporting the load and resisting the interface failure and the failure may occur to the fibre before the interface. Larger interfacial area also lowers the intrinsic bond strength and the interfacial shear strength. In multiple fibre pullout test, interfacial area will be the sum of the interfacial areas.

Schematic diagram illustrated in Fig. 1 shows an angle of contact which is very important parameter in measuring the interfacial properties. There will be a component of the force acting perpendicular to the fibre bundle and compress the matrix against the fibre bundle. This force will be $\mathrm{F} \operatorname{Cot} \theta$ denoted by $\mathrm{F}_{\mathrm{c}}$, where $\mathrm{F}$ is the applied force. This force is the sum of the interfacial bond strength $\left(\mathrm{F}_{\mathrm{ad}}\right)$ as well as the frictional forces. It can be written as

$$
\mathrm{F}=\mathrm{F}_{\mathrm{ad}}+\mu \mathrm{F}_{\mathrm{c}}
$$

Peak pull-out force $\left(\mathrm{F}_{\mathrm{p}}\right)$ which can occur after debonding due to the build up of frictional stress which can be calculated from the equation

$$
\mathrm{F}_{\mathrm{p}}=\tau \mathrm{A}+\mu \mathrm{F}_{\mathrm{f}} \cot \theta
$$

where $F_{f}$ is the frictional force and $\tau_{f}$ is the frictional shear stress, $A$ is the interface area

in $\mathrm{mm}^{2}, \mu$ is the static coefficient of friction as the pullout occurs at a very small rate of 1-5 $\mathrm{mm} / \mathrm{min}$, and $\tau$ is the bond strength in $\mathrm{MPa} ; \theta$ is the contact angle of the fiber bundle with the resin droplet. Coefficient of friction keeps on changing from the onset of friction to a static value after debonding during the frictional sliding. All these stages can be observed in the load-deflection plot (Fig. 7). Interfacial shear stress (IFSS) is obtained by dividing Eq. (5) with cylindrical area [28-30].

$$
\mathrm{F}_{\mathrm{p}} / \mathrm{A}=\mathrm{IFSS}=\tau+\tau_{\mathrm{f}} \mu \cot \theta
$$

\section{Experimental}

In order to determine the shear strength of the interface between the fibre and the matrix, a shear force is being exerted to displace one phase relative to the other. This is done by holding the matrix material and exerting a tensile force to the fibre. The fibres of small diameter are likely to have a low breaking strength. If the force required for shearing the interfacial bond is greater than that which the fibre can sustain in tension, the fibre will rupture first and abort the bond strength measurement. In micro-bond pullout technique, the small value of interfacial contact area assures that de-bonding will occur before the rupture of fibre bundle and before matrix deformation. The possibility of failure of the fabric before the interface failure can also be eliminated by using multiple fibre pullout technique.

PE and PP are the systems used for this study (Tables 1, 2). 25 samples were prepared for processing. (Details of sample preparation are explained in the next section.) After thermal processing, 12-15 samples with proper blob formation were selected for testing. A microvise is used to grip the droplet-fibre assembly on Instron 8801. Under loading condition, Blob gets sheared off the fibre bundle with a strain rate of $2 \mathrm{~mm} / \mathrm{min}$ (Fig. 3). Keeping a low strain rate reduces the compliance related 
Table 1 Manufacturing parameters and properties of matrix materials

\begin{tabular}{lll}
\hline Property & HDPE & PPa \\
\hline Density & $0.95 \mathrm{~g} / \mathrm{cc}$ & $0.92 \mathrm{~g} / \mathrm{cc}$ \\
Melting temperature & $125^{\circ} \mathrm{C}$ & $171^{\circ} \mathrm{C}$ \\
$\mathrm{T}_{\mathrm{g}}$ & $-125^{\circ} \mathrm{C}$ & $-20^{\circ} \mathrm{C}$ \\
Apparent matrix viscosity $\left(190^{\circ} \mathrm{C}\right)$ & $140 \mathrm{Ns} / \mathrm{m}^{2}$ & $75 \mathrm{Ns} / \mathrm{m}^{2}$ \\
@ shear Rate $1000 \mathrm{~s}^{-1}$ & & \\
\hline
\end{tabular}

Table 2 Manufacturing parameters and properties of reinforcing materials

\begin{tabular}{lll}
\hline Property & PE/PET copolymer & Coated iPP fabric \\
\hline Density & $0.95 \mathrm{~g} / \mathrm{cc}$ & $0.9 \mathrm{~g} / \mathrm{cc}$ \\
Melting point & $270^{\circ} \mathrm{C}$ & $279^{\circ} \mathrm{C}$ \\
Time of heating & $45 \mathrm{~min}$ & $45 \mathrm{~min}$ \\
Fiber surface & Untreated & Coated \\
Strain rate & $2 \mathrm{~mm} / \mathrm{min}$ & $2 \mathrm{~mm} / \mathrm{min}$ \\
\hline
\end{tabular}

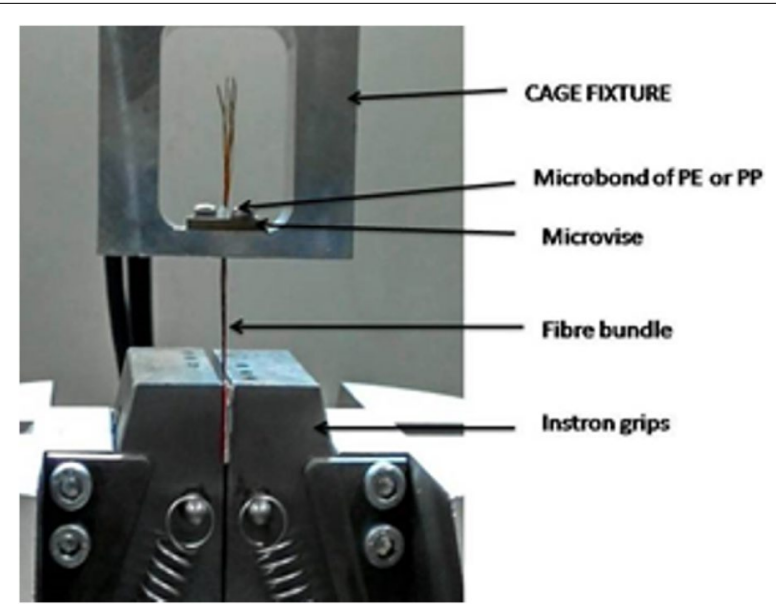

Fig. 3 Fibre pullout test on Instron

problems. Microvise is screwed with an aluminum cage in order to attach with the testing machine. One end of the fibre bundles is gripped with the Instron with the help of sand paper and the blob is supported by the slot in the microvise. While applying the displacement, the blob's lower part gets compressed by the slit of the microvise and the interface is subjected to shear. As the shear strength of the blob and the interface is smaller than the compressive strength of the matrix, the blob shears through the fibre bundle. Twelve samples of PP were failed properly (six samples with four fibre bundle and six samples with eight fibre bundle) while 10 samples of PE failed in desired fashion. Reason for rejection of samples before testing was improper or irregular formation of blob around the fibre bundle. Some of the test results were rejected when the individual fibre was seen pulled out instead of the fibre bundle as a whole. 

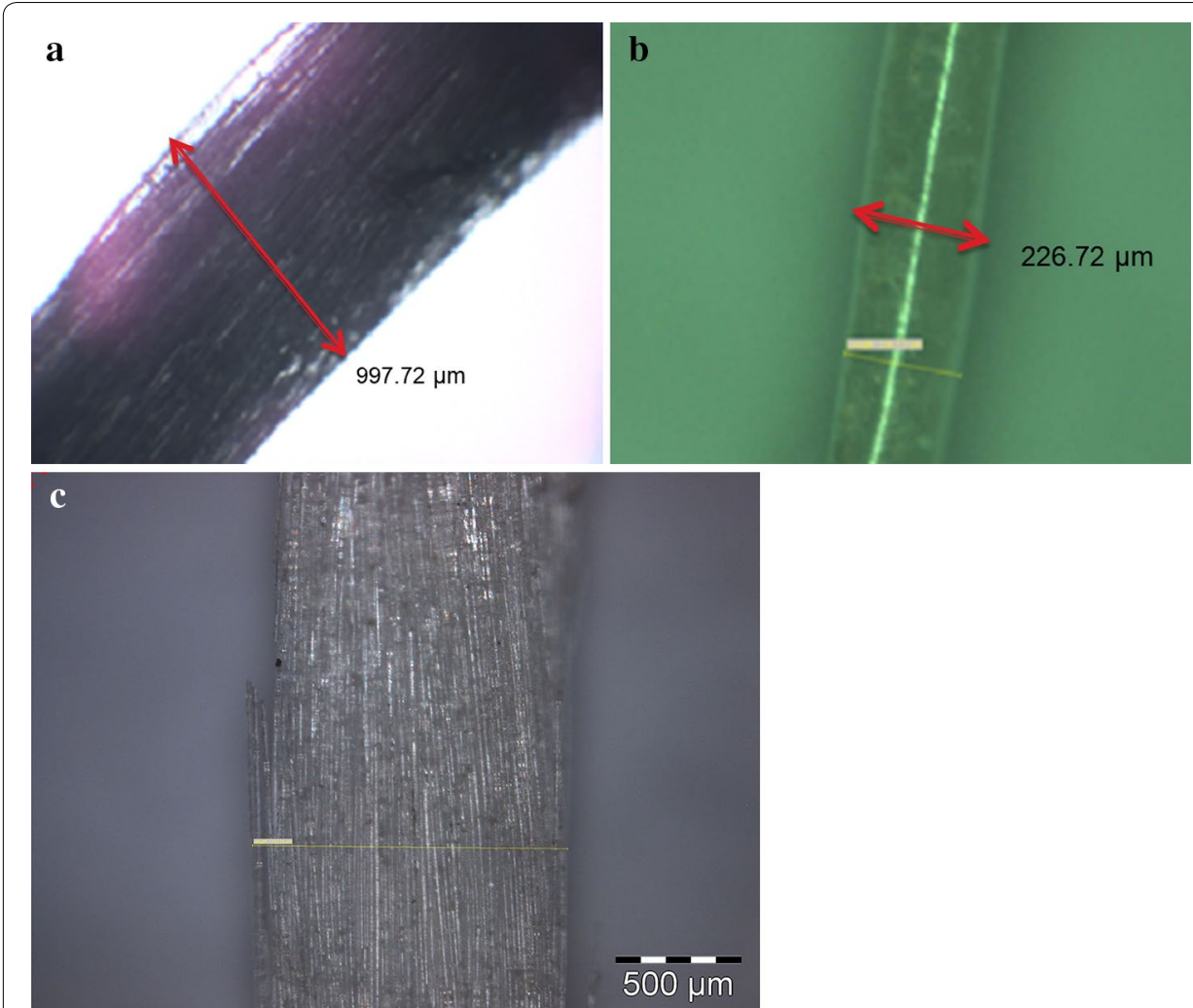

Fig. 4 a Fibre diameter measurement (PE), b fibre diameter measurement (PP), c fibre diameter measurement with the individual fibres in single bundle (PE)

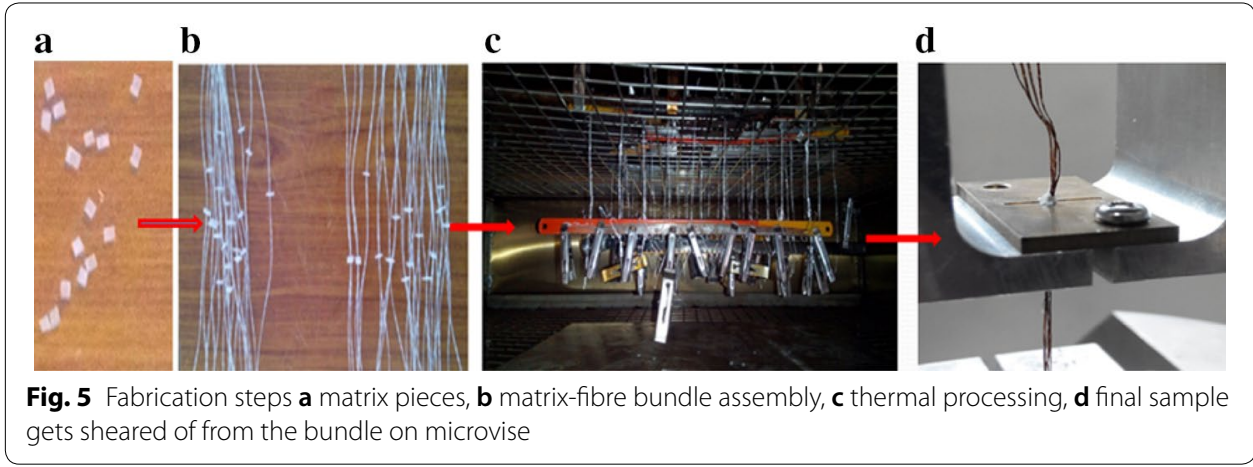

\section{Processing and fabrication}

Samples are prepared with fibre bundles extracted from the commercially available fabrics of PE and PP. These fibres are observed under optical microscopy in order to determine the fibre dimensions (Fig. 4a, b). Olympus BX 61 model optical microscope with working capabilities of reflection/transmission and bright field/dark field and a maximum magnification up to $1000 \times$ is used for this purpose. The fabrication procedure starts by inserting extracted fibre bundles through the hole made on tiny polymer sheets such that the matrix forms a droplet or blob around the polymer fibre bundle after heat treatment (Fig. 5). The fibres are well arranged and wrapped with aluminium foil to hold 
them together and sand paper is used to grip them well in the Instron. This improves the possibility of every fibre bundles get pulled out at the same time. When the matrix has hardened or been cured, the fibre diameter and the droplet dimensions are measured through optical microscopy and the interfacial contact area is determined. Each fibre extracted from the fabric was a bunch of small fibres as in optical microscopic Fig. 4c. Thus, each extracted fibre is called as a 'fibre bundle' in this literature. If 3 such 'fibre bundles' are used, it is called 3 fibre bundle and so on. Individual fibre bundle of PE has an average diameter of $990 \mu \mathrm{m}$. And for individual fibre has a diameter of $18 \mu \mathrm{m}$. Actual cross section of the fibre bundle is oblong. But the fibre bundle is assumed to be cylindrical in shape.

In order to study the failure pattern in detail, failed samples were coated with gold and observed through scanning electron microscopy (SEM). ZEISS EVO 18 scanning microscope is used for the fractography with a coupled assistance from smartSEM software. Electron beam generated from Lanthanum hexaboride $\left(\mathrm{LaB}_{6}\right)$ gun is passed through gold coated samples of PE and PP. These non-conducting samples were gold coated for $90 \mathrm{~s}$. An optimum coating is required to get a clear image avoiding static electricity generation or 'charging. With an accelerating voltage of $5 \mathrm{kV}$, various fracture features could be studied from the micrographs. Extensive fractography is carried out on failed sample of all the mesomechanical, quasi-static and drop mass impact tests using Carl Zeiss Optics of the equipment which could magnify the samples from $30 \times$ to $800 \times$ for clear view and images (Fig. 6a, b).

\section{Results and discussion}

Polyethylene samples of three fibre bundles polypropylene samples with eight and four fibre bundles are tested as shown in Fig. 3 and the pull-out force vs extension results are plotted in Fig. 7. Various parameters and details of the maximum force obtained from the test is tabulated in Table 3. PP fibres were thinner compared to PE fibres. As multiple fibre bundle pull-out test is a volume fraction driven test, in order to compare the interface properties of these two materials, it was required to include more number of fibres in PP than PE. Post fracture optical microscopy shows a clear image of the matrix sheared through the fibre bundle (Fig. 8). It reveals that the fibres are infiltrated by the matrix. Matrix wets the surface of each fibre infusing into the bundle. Thus, actual surface area is irregularly wavy in nature. Still, the surface area is assumed to be cylindrical

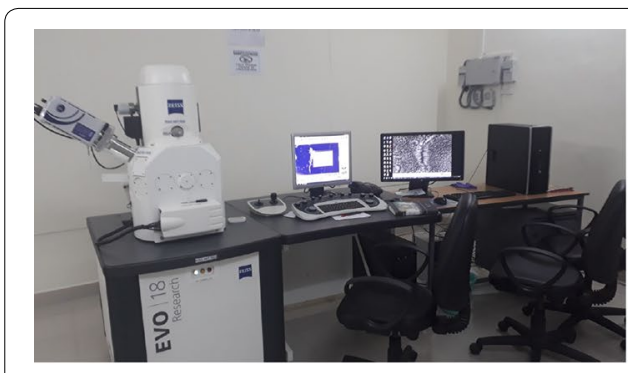

a Optical microscope

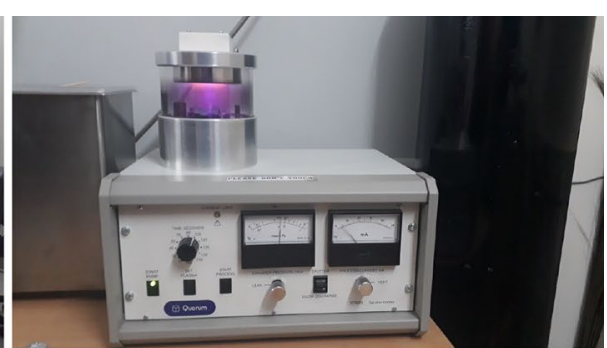

b Gold coating machine

Fig. 6 a Optical microscope, b gold coating machine 

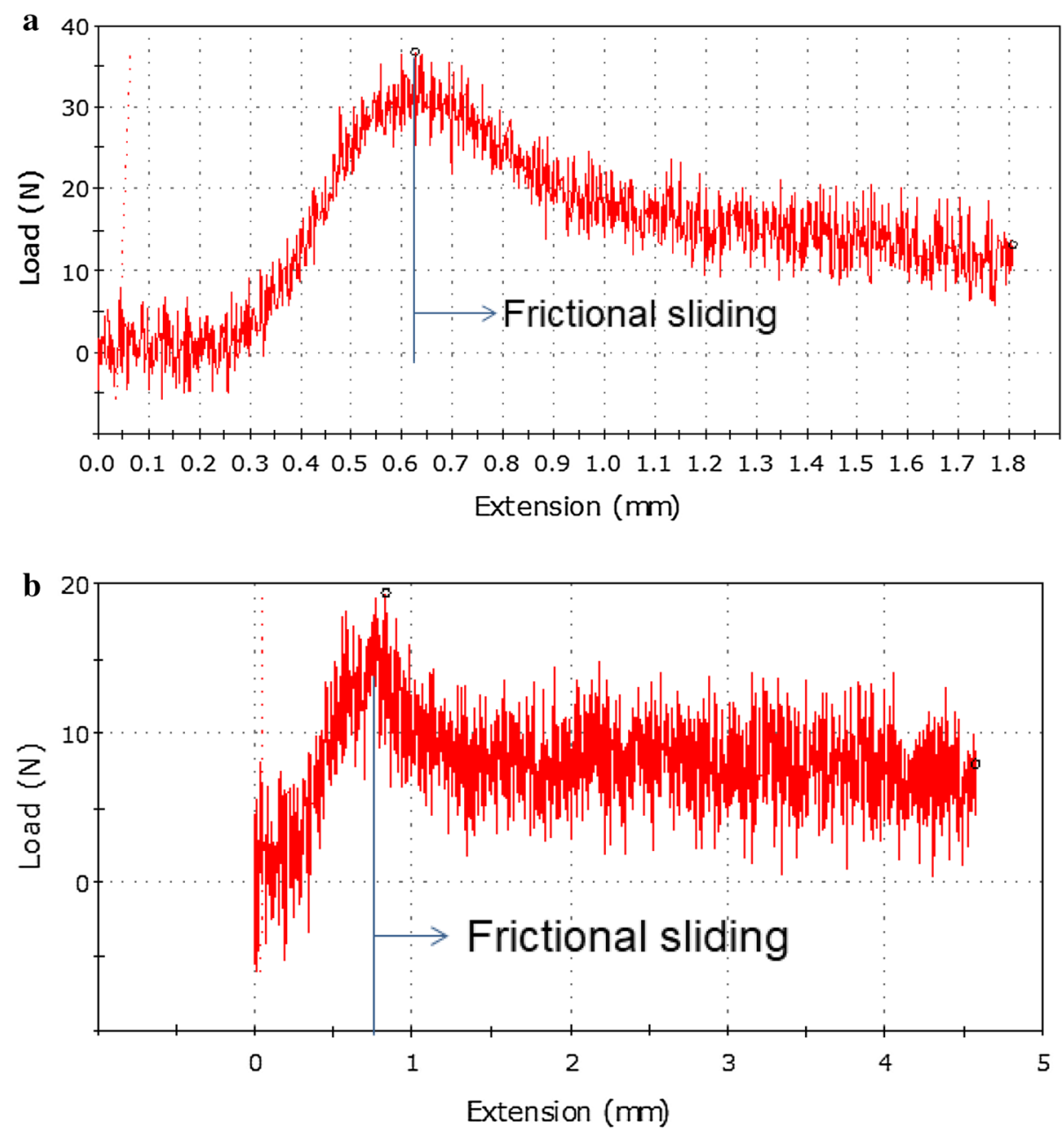

Fig. 7 a Sample load vs extension curve (PP), b sample load vs extension curve (PE)

to reduce the complexity. This results in getting reduced intrinsic bond strength than the actual bond strength.

As per the literature, interfacial crack initiates at some point at the interface close to the fibre entry and propagates along the embedded length towards the opposite fibre end. After the initial crack the frictional force between the debonded matrix and fibre gets added up in the further debonding mechanism. The crack would have initiated at a certain location inside the bundle due to voids, low matrix distribution, residual stresses etc. Still, due to the frictional effects between the fibre surface and the matrix, actual maximum load reached is higher than the initial debonding force [11]. When the crack propagates through the interface that will contribute more than the internally developed cracks as the entire fibre bundles are pulled out of the matrix together.

Various interfacial properties like interfacial shear stress and interfacial shear strength along with coefficient of friction of the PP and PE SRPCs were evaluated by mesomechanical method of microbond bundle pullout test. For PP SRC, in the micro-bundle pullout test, the maximum force of de-bonding can be evaluated to be 25 to $27 \mathrm{~N}$ with respect to the maximum pull-out force of 28 to $30 \mathrm{~N}$ including the frictional forces. The 
Table 3 Major parameters of microbond bundle pullout test PE and PP

\begin{tabular}{llll}
\hline & Max load (N) & Bundle avg diameter $(\mathbf{m m})$ & $\begin{array}{l}\text { Drop } \\
\text { length } \\
(\mathbf{m m})\end{array}$ \\
\hline PE 3 fibre bundle & & 2.30 \\
Mean & 14.28 & 4.18 & 2.61 \\
Maximum & 19.47 & 4.67 & 2.05 \\
Minimum & 11.6 & 4 & 0.20 \\
Standard deviation & 2.89 & 0.230 & \\
PP 8 fibre bundle & & & 2.30 \\
Mean & 26.21 & 0.587 & 2.61 \\
Maximum & 31.61 & 0.682 & 2.05 \\
Minimum & 20.89 & 0.517 & 0.20 \\
Standard deviation & 3.93 & 0.060 & 1.69 \\
PP 4 fibre bundle & & & 1.91 \\
Mean & 24.16 & 0.80 & 1.51 \\
Maximum & 36.69 & 0.97 & 0.15 \\
Minimum & 8.41 & 0.58 & \\
Standard deviation & 12.72 & 0.16 & \\
\hline
\end{tabular}

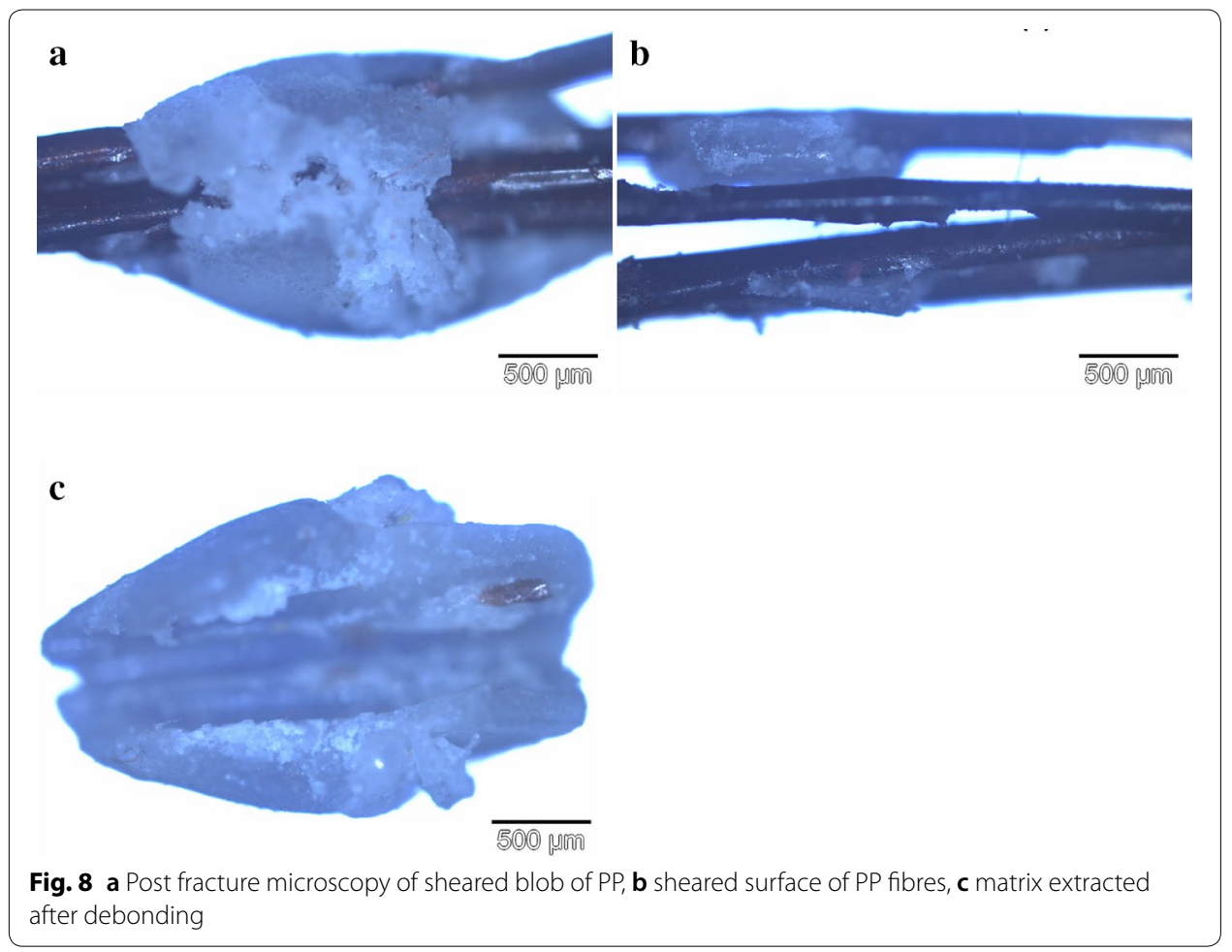

frictional stress at onset is about 14 to $15 \mathrm{MPa}$ and the frictional sliding stress is about 7 to $8 \mathrm{MPa}$. For PE, In the microbundle pull-out test, the maximum de-bonding force can be evaluated to be in the range of 14 to $18 \mathrm{~N}$ while the maximum pull-out force of 20 to $25 \mathrm{~N}$. The frictional onset stress varies from 3 to $5 \mathrm{MPa}$ and the frictional sliding stress varies from 1 to $3 \mathrm{MPa}$. Test was repeated with a different bundle size by changing 
the number of fibres in the bundle to reduce the scattering in the load, and a maximum pullout force of $21.25 \mathrm{~N}$ needed for failure to occur. The maximum compressive force is found to be $14.08 \mathrm{~N}$. The frictional onset stress was found to be approximately $0.440 \mathrm{MPa}$ and the frictional sliding stress was around $0.117 \mathrm{MPa}$.

\section{Pull-out characteristics of polyethylene self reinforced composite}

Figure $9 \mathrm{a}-\mathrm{k}$ show the variation of interface properties with the drop length for different set of samples with three fibres. It is noted that the load at which the bond breaks is influenced by the drop length. This may be due to the reduction in contact area in multiple fibre bundles. Peak pullout force depends on debonding force as well as the frictional forces. Multiple fibre bundle gives a more reliable idea about the peak pullout
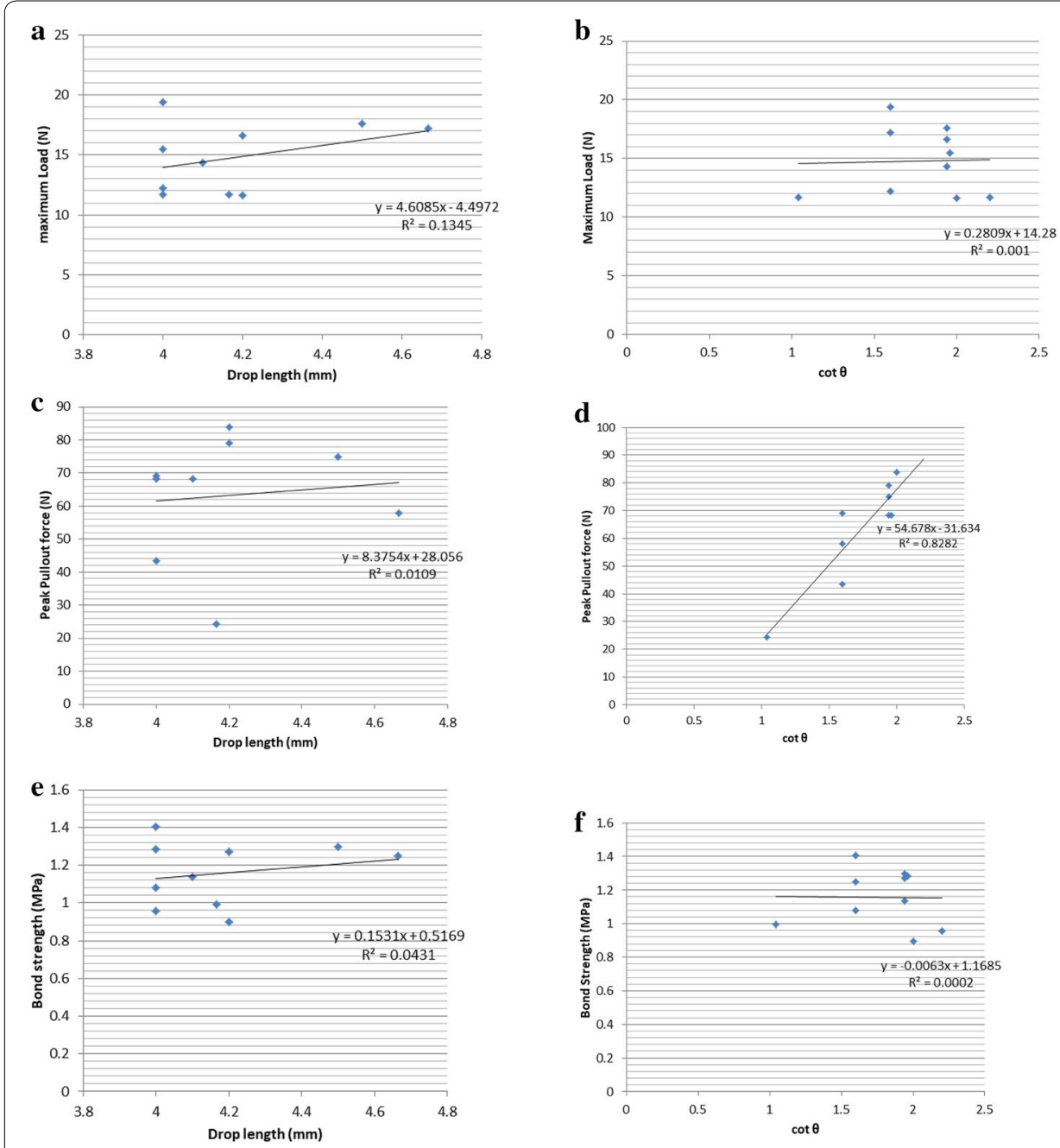

Fig. 9 a Max. load vs drop length graph of PE microbond tests, $\mathbf{b}$ max. load vs contact angle graph of PE microbond tests, $\mathbf{c}$ peak pullout force vs drop length graph of PE microbond tests, $\mathbf{d}$ peak pullout vs contact angle graph of PE microbond tests, e bond strength vs drop length graph of PE microbond tests, $\mathbf{f}$ bond strength vs contact angle graph of PE microbond tests, $\mathbf{g}$ IFSS vs drop length graph of PE microbond tests, h IFSS vs contact angle graph of PE microbond tests, i frictional stress vs drop length graph of PE microbond tests, $\mathbf{j}$ frictional stress vs contact angle graph of PE microbond tests, $\mathbf{k}$ coefficient of friction vs drop length graph of PE microbond tests 


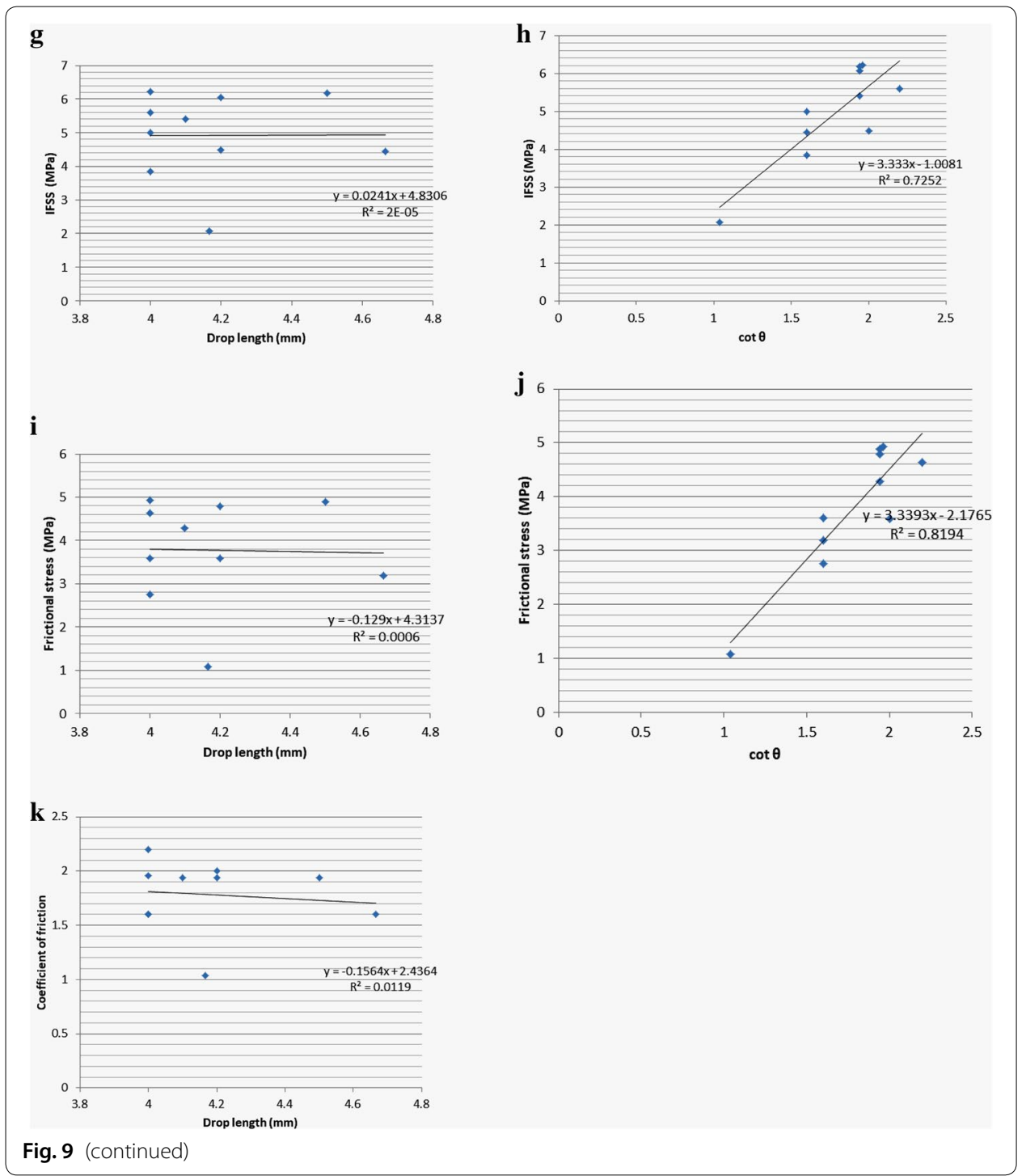

force which is inclusive of the bond strength and the frictional stress. Increasing contact angle has an adverse effect of frictional stress due to reduced wetting which is evident from Fig. 9j.

Peak pull-out force is the resultant force experienced by the blob after de-bonding. It is the sum of the peak de-bonding force and the frictional forces. Two values of $y$-intercept are the frictional force $F_{f}$, frictional stress produced when the blob slides over the fibre/ fibre bundle.

Drop length (l) of the matrix over the fibre bundle is an important parameter. If the drop length is more the fibre may fail before a total interface failure. The critical embedded length $\left(l_{c}\right)$ or the limiting value of the embedded length can be obtained from the simple relationship

$$
\mathrm{l}_{\mathrm{c}}=\sigma_{\mathrm{f}} \mathrm{D} / 4 \tau
$$


where $\sigma_{\mathrm{f}}$ is the ultimate fibre tensile strength at break, $\mathrm{D}$ is the fibre diameter and $\tau$ is the shear strength of the bond.

Maximum load, peak pullout force, bond strength, frictional properties, IFSS are the major factors evaluated in the study and the effect of these parameters with drop length and contact angle are analysed in this study. Since, all these parameters are in linear relationship with drop length and $\cot \theta$, a linear curve fitting is adopted in all the cases $(\theta$ in degrees).

Frictional stress at peak load shows a decreasing trend. This may be due to the reduction in contact area in multiple fibre bundles. Peak pullout force depends on debonding force as well as the frictional forces. Multiple fibre bundle gives a more consistent idea about the peak pullout force which is inclusive of the bond strength and the frictional stress. As the bond strength is exclusively depending upon the maximum load and the contact area, multiple fibre bond strength values are more reliable than the single fibre bond strength due to the statistical relevance indicating the relevance of multiple fibre pullout test over the single fibre pullout test. Slope of bond strength shows a decreasing tendency and increasing contact angle has an adverse effect on frictional stress. Polyolyfins are having comparatively low surface energies. Due to this the surfaces of these materials have lower wettability. In SRCs, both the matrix and reinforcement are being the same, better wettability can be obtained. If the wettability is less, the liquid forms a more spherical blob reducing the contact area between fibre and the matrix resulting in higher contact angle and thus less frictional stress too.

Figure 9k shows that the coefficient of friction in monotonic sliding is almost independent of the microbond drop length of polyethylene matrix. Polyethylene surfaces are generally known for a lubricating surface with low sliding coefficient of friction values. As the matrix solidifying shrinkage pressure on the fibre surface is manifested here as the coefficient of friction of the material on itself as a counter-face, the values appear to be only dependent on the surfaces indicating higher values and not on the length of the bond.

\section{Characteristics of polypropylene (PP) self reinforced composite by microbond multiple fibre pullout tests}

Figure 10a-k represents the characteristics of various interfacial parameters of PP SRCs. Maximum load required to break the interfacial bond between the matrix and the fibre bundle shows a positive slope when plotted against drop length with higher slope for fibre bundles. Peak load is the sum of the maximum load and the frictional force. Intercept of this curve with y-axis gives the frictional force. As the number of fibres are more in eight fibre bundle, frictional force is also high with less slope. Bond strength seems to be getting reduced with increasing drop length for eight fibre bundle which could be due to the lesser dispersion of matrix material into the fibre bundle. Contact angle plays an important role in interfacial properties as mentioned in the previous session. Higher contact angle indicates lower wettability and reduced interfacial strength due to low surface energy. When the fibres are more, bond strength will be slightly higher. Interfacial shear stress is consistent for all the drop lengths considered in the analysis indicating consistency of the results. A minimum length of the drop required to maintain a proper bond between the matrix and the fibres which is called the critical drop length. 
Increasing contact angle has an adverse effect on interfacial shear stress which is more severe in the case of four fibre bundles due to less contact surface. Frictional stress is also showing the similar trend with increasing contact angle and showing less influence with the changing drop length above the critical length. Coefficient of friction is showing opposite slopes in four fibre bundle and eight fibre bundle. This could be due to the influence of minute changes in surfaces in contact when contact angle changes on coefficient of friction.

Weak interface in PE and cause of high scatter in PE can also be perceived in chemical bonding aspects. PE is formed by long chaining of carbon with two hydrogen attached to each carbon atom. After processing, polyethylene fibre and matrix surfaces adhere each other and weak hydrogen bonds will be formed. This influences the test and increases the scattering in the results. While in PP, there is a possibility of different

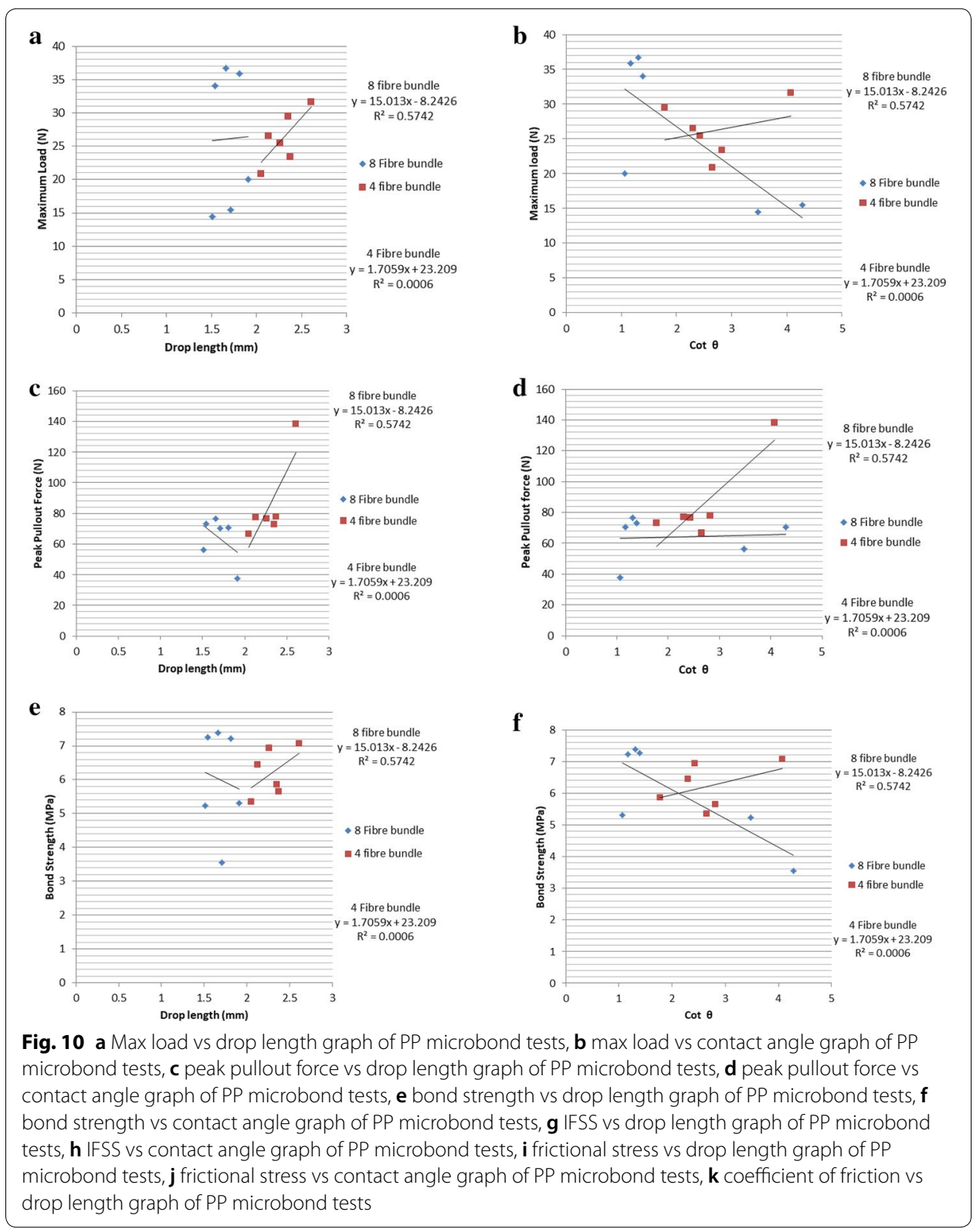



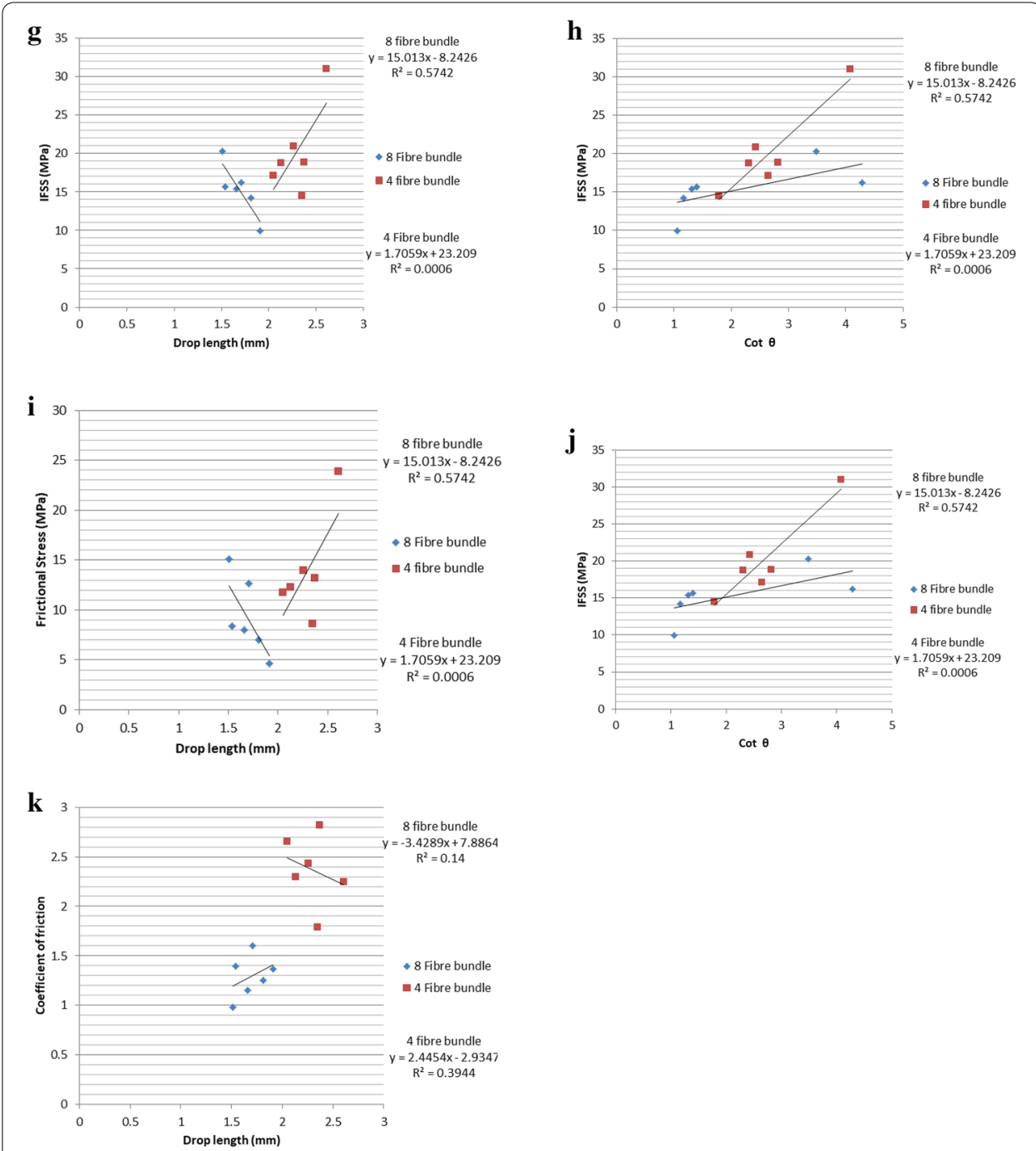

Fig. 10 (continued)

bonds of $\mathrm{CH}_{3}-\mathrm{CH}_{3}, \mathrm{H}-\mathrm{H}$ and $\mathrm{CH}_{3}-\mathrm{H}$. This improves the adhesion between PP fibre and the matrix. PP matrix was more infused into the fibre bundle than it's couterpart. This improves the adhesion in PP than PE. All these emphasise that the selection of the method of analysis is highly influenced by the material to be selected.

\section{Fourier transform infrared spectroscopy (FT-IR)}

Attenuated total reflectance (ATR)-FTIR is one of the interface characterization method in which a beam of infrared radiation (IR) is being transmitted through the specimen. Some amount of the IR is absorbed, emitted or transmitted through the specimen. These properties of the materials are related to variations in the energy states of the material interacting with the radiation. Absorption causes changes in the vibrational energy 

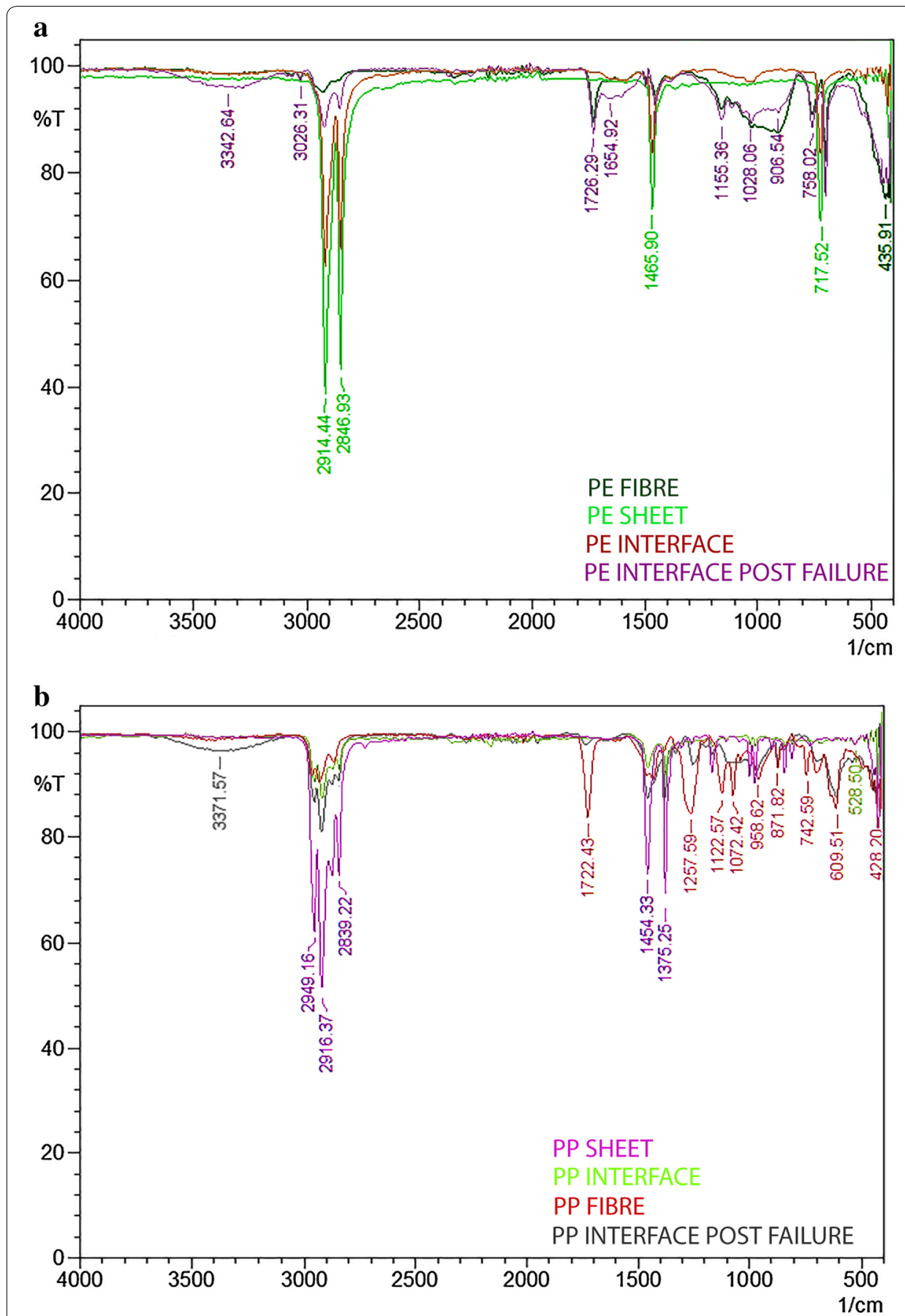

Fig. 11 a Fourier transform infrared spectroscopy of polyethylene (PE), b Fourier transform infrared spectroscopy of polypropylene (PP)

states in the IR region. Based on the nature of absorption at a specific frequency level, information about the molecular structure can be obtained. FT-IR conducted on PP and PE pullout samples in order to analyse if there any changes in molecular bonds when the interface is formed which support the interface properties [31-34]. 
Peaks within the wavenumber range of $4000-1400 \mathrm{~cm}^{-1}$ explain the functional groups in the material, while analyzing the range below $1400 \mathrm{~cm}^{-1}$ (finger print region) needs additional information. Figure 11a is the comparison of FT-IR spectroscopy of the polyethylene (PE) sheet, fabric, pre-failure pullout samples and post failure pullout samples. There are no double bonds in the molecular structure of PE but having $\mathrm{C}-\mathrm{C}$ bonds and $\mathrm{C}-\mathrm{H}$ bonds in its molecular structure. For PE sheet, peaks at $2914 \mathrm{~cm}^{-1}$ and $2846 \mathrm{~cm}^{-1}$ represent two $\mathrm{C}-\mathrm{H}$ stretching bonds. $\mathrm{C}-\mathrm{H}$ bending is represented at $1465 \mathrm{~cm}^{-1}$ and $\mathrm{C}-\mathrm{C}$ bond stretching is at a wavenumber of $717 \mathrm{~cm}^{-1}$. Some information about adsorption can be obtained by analyzing these regions. There is an additional peak at $1726 \mathrm{~cm}^{-1}$ for the fibre which indicates the presence of another functional group. This is because the fibre is not pure polyethylene but a copolymer of PE and polyethylene terephthalate (PET). The carbonyl group present in the PET molecule is absorbing the radiation in $1700 \mathrm{~cm}^{-1}$ wavenumber range. Wave numbers of pre-failure and post failure samples were almost same as that of the untreated matrix materials which further indicates that there are no changes to the functional groups due to thermal processing. Adsorption on the surface of fibres may indicate additional peaks in FTIR, but the failed samples do not indicate any such peaks. Moreover, most of the pre fracture samples as well as post fracture samples were having almost same distribution as its matrix.

In Fig. 11b, for PP, the peaks are at $2949.16 \mathrm{~cm}^{-1}, 2916.37 \mathrm{~cm}^{-1}$ and $2839.22 \mathrm{~cm}^{-1}$ which indicate $\mathrm{C}-\mathrm{H}$ stretching that is present in the molecular structure. Peaks at $1453 \mathrm{~cm}^{-1}$ and $1375.25 \mathrm{~cm}^{-1}$ indicate $\mathrm{C}-\mathrm{C}$ bonds and $\mathrm{C}-\mathrm{CH}_{3}$ bonds. An additional peak at $1722.43 \mathrm{~cm}^{-1}$ for fibre indicates possibility of a coating which is not present after thermal processing. In both the FTIR spectra after failure, additional peaks of $3342 \mathrm{~cm}^{-1}$ and $3371 \mathrm{~cm}^{-1}$ indicate surface adsorption. This is different from the PE samples where there is no adsorption related effects and could have contributed to the intrinsic bond strength that was observed in PP samples.

\section{Micromechanical comparison}

Figure 12 shows a comparison between IFSS calculated from Rosen's, Chamis models with that of pullout test of PE SRC. IFSS obtained from pullout test seems to be more conservative compared to the micromechanical calculations. Chami's and Rosen's formulations are neglecting the adhesion related parameters like contact angle, contact surface area and embedded length. Also it does not consider matrix solidification shrinkage pressure while the blob is formed. This could be the reason for the difference in experimental mesomechanical IFSS values and micromechanical calculations even though the micromechanical expressions are addressing the volume fraction. Table 4 is a comparative table for IFSS obtained experimentally and analytically.

\section{(a) Fractography for PE SRC under scanning electron microscopy (SEM)}

The objective of SEM is to analyse the interface between fibre and matrix and to analyse the following features in detail after pullout. (1) Failure pattern, (2) to check wether any major fibre failure has occurred, (3) to gather information about the fibre surface after pullout, (4) to analyse how the blob surface has supported the load when in contact with the microvise (5) to check details about the matrix adhesion on the fibre surface (6) to 

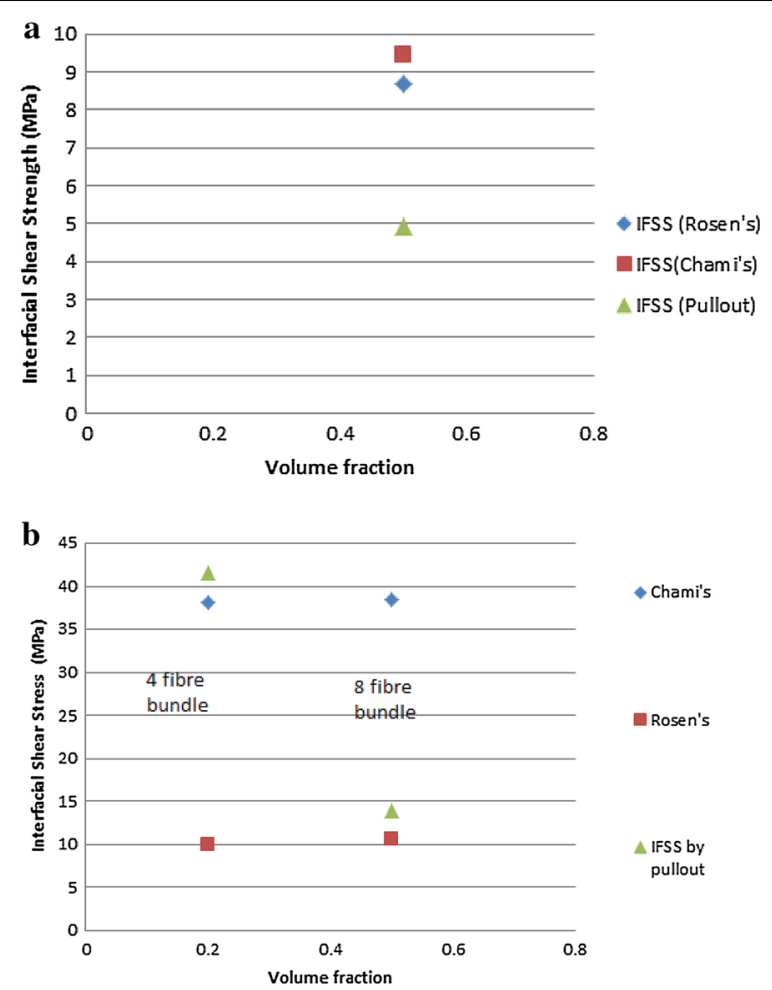

Fig. 12 a Comparison of IFSS of PE by micromechanical and mesomechanical methods. $\mathbf{b}$ Comparison of IFSS of PP by micromechanical and mesomechanical methods

Table 4 IFSS evaluated through analytical and experimental methods for PE and PP

\begin{tabular}{lccc}
\hline Material & IFSS (Rosen's) (MPa) & IFSS (Chamis') (MPa) & $\begin{array}{c}\text { IFSS } \\
\text { from pull- } \\
\text { out (MPa) }\end{array}$ \\
\hline PE (3 fibre bundle) & 8.9 & 9.1 & 4.8 \\
PP (4 fibre bundle) & 38.4 & 10.6 & 41.58 \\
PP (8 fibre bundle) & 39.27 & 11.27 & 15.32 \\
\hline
\end{tabular}

study the influence of thermal processing in the interface (7) the diffusion of matrix into the fibre bundle in order to get a strong interface [14-20]. Here, all these factors are analysed with the help of SEM images of PE and PP post pullout samples. Figure 13a indicates failure of a few number of fibres along with the interface failure and matrix adhesion on the failed surface.

Figure 13b shows an opposite edge where the blob has slightly bulged at the middle and an improper dispersion of matrix has occurred at the interface. The fibre has suffered a surface scratch due to pullout over the surface which can be visulaised in Fig. 13c, $\mathrm{d}$. The shape of the blob and the acute contact angle along with the failed interface and scratched fibre surfaces are visible in Fig. 13e. 


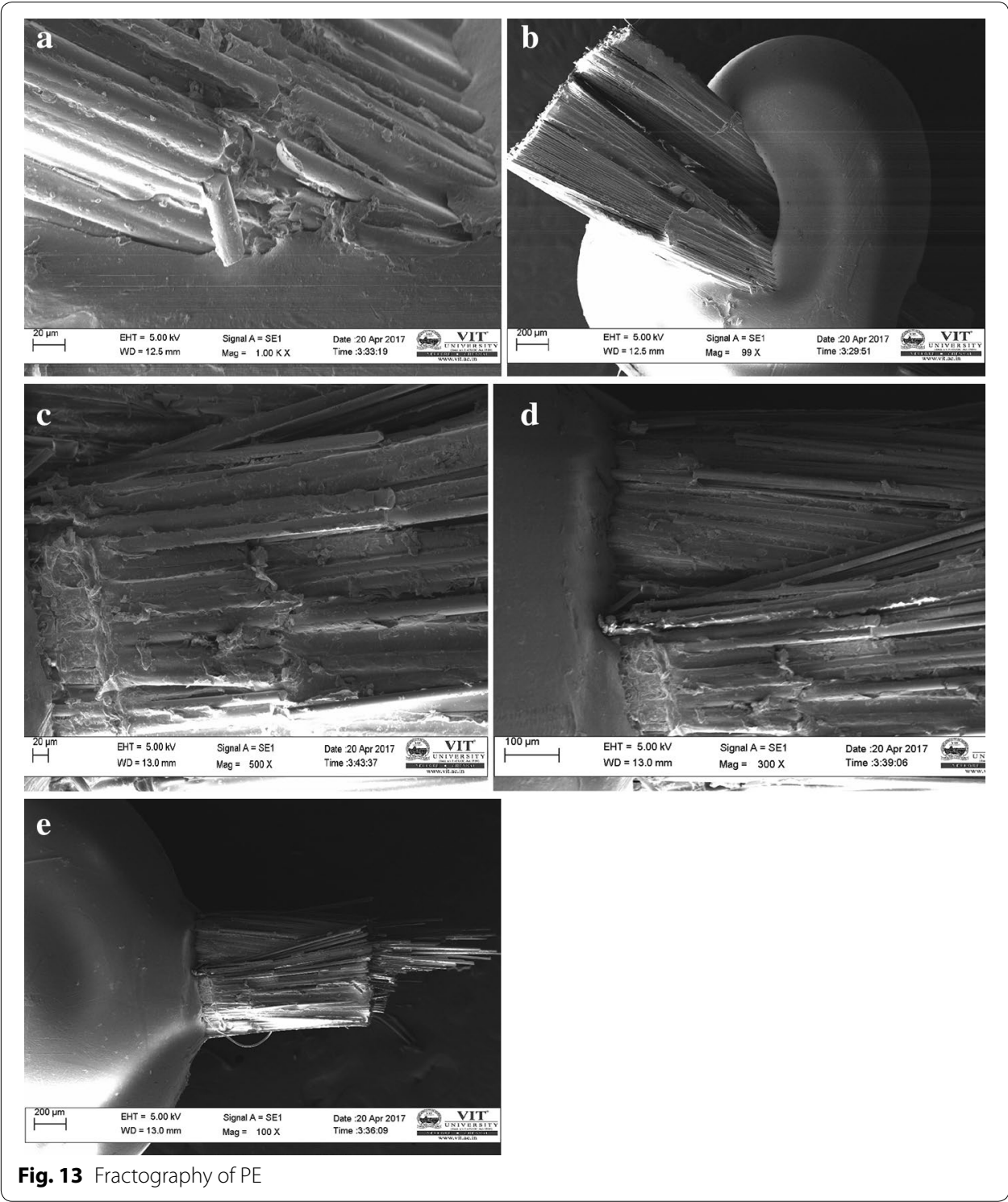

(b) Fractography for PP SRC under scanning electron microscopy (SEM)

Nishikawa et al. [35] reported how the extent of matrix cracking is an essential parameter to determine the interface properties from microbond tests. A "pure debonding process" was explained by them at which the fibre pullout was completed by the debonding of the entire surface. Images of the fractured and failed blobs from the microscopy exhibit a rough surface morphology for the thermally processed PP blob (Fig. 14a-c). Fibre surface appears to be coated and the pullout on the surfaces are seen to cause a loss of coating (Fig. 14d). Location of crack initiation at the tip of the blob is visible in Fig. 14d. It is also evident that even if the crack has propagated along the matrix but the major contribution to the fracture is along the interface. Compressive contact between the microvise and the blob is seen to result in a pullout type of failure at the microvise exit end (e). As the interfacial bond strength is better in the case of PP SRC compared to PE SRC, the fibre-matrix interface is more coated with a modified zone of the PP matrix 


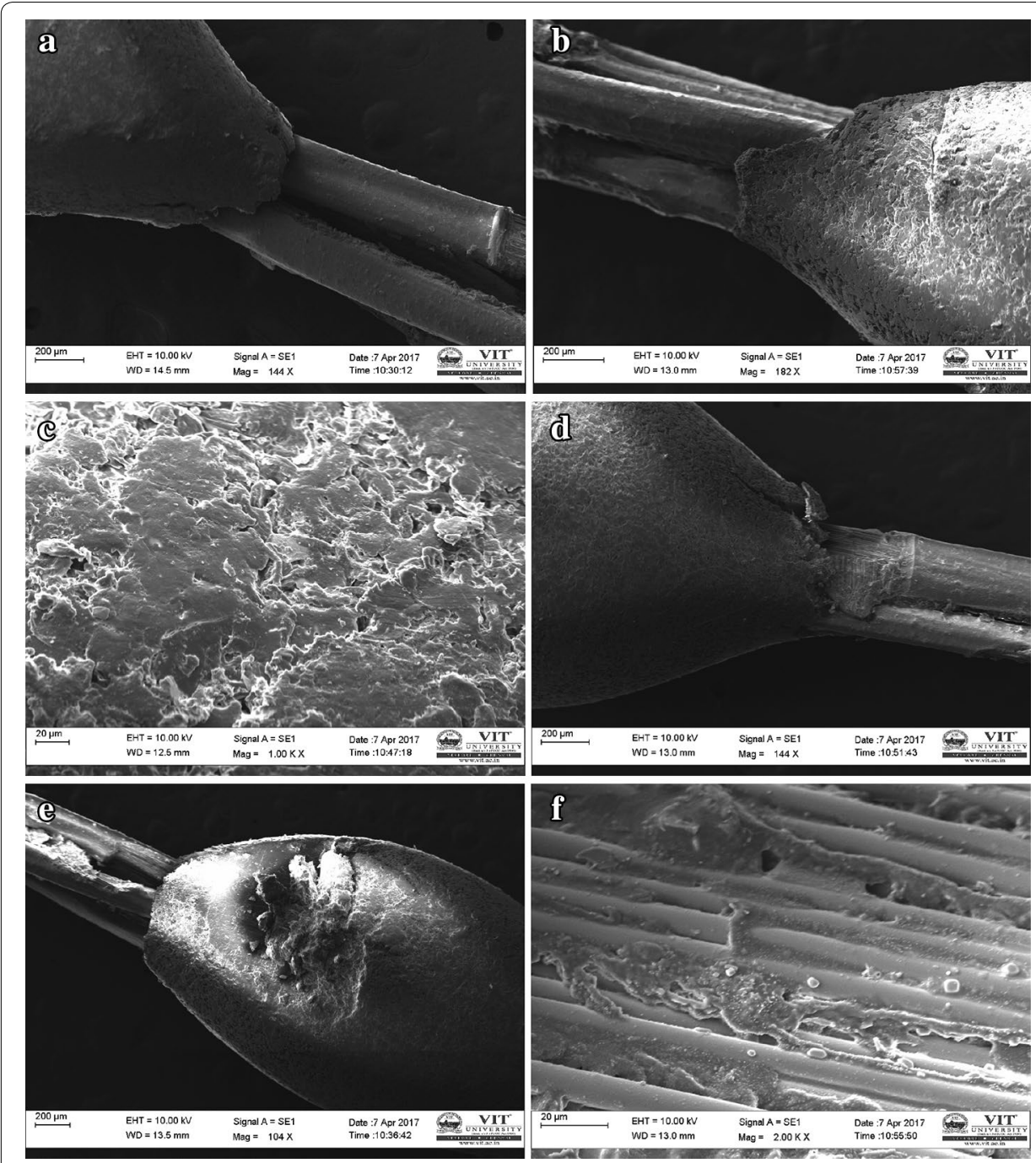

Fig. 14 Fractography of PP

in the first case than in the second case where the PE/PE interface is seen to be weaker with the fibre bundle exhibiting considerable matrix cracking along the fibre direction and perpendicular to it. The PP/PP fracture morphology as depicted in Fig. 14f is seen to reflect a stronger nature of the interfacial adhesion between the PP matrix and fibre. Here, it is noteworthy that the longitudinal and transverse matrix cracking is almost absent. Results from pullout test also validate these observations where the shear pull out of the entire blob is evident.

\section{Conclusions}

Mechanical properties of the composite materials are highly related to their interface adhesion. In the current study, tiny blobs of polymer matrix is prepared on a bundle of polymer fibres taken out from the polymer fabric and with the help of a micro-vise the interfacial pullout load is evaluated. The interfacial shear and frictional properties are also evaluated with the geometric properties of the blob and surface tension 
properties. Multiple fibre bundle pullout technique is a reliable alternative choice over the conventional single fibre pullout tests in many aspects as it is a statistically averaged test method. Single fibre pullout test fails in many cases when the fibre load under tensile loading condition is lower than the load taken by the fibre-interface. Thus by multiple fibre pullout technique, it was found that the interfacial shear strength of the polypropylene and polyethylene self reinforced polymer composites are comparable to conventional fibre reinforced polymer composites, though on the lesser side. Polypropylene (PP) based self-reinforced composites (SRC) showed better interfacial strength compared to polyethylene (PE) based self reinforced composites due to more lubricating nature of the polyethylene and weak wettability. PP matrix infuses into the gaps of the individual fibres and results in a strong interface which was not observed in PE SRCs in microscopic examinations indicating the reason for weak interface. The adsorption in PP SRCs indicated by FTIR spectroscopy was also absent in the PE SRCs there by providing one of the reasons for a superior IFSS in the PP SRCs compared to the PE SRCs. Micrographs show that PP is more infused into the fibre bundle and fractographic studies substantiated the objective of this analysis. It can also be concluded that the selection of the method of interface analysis is also depending upon the nature of the fibre and matrix materials as PE results are more scattered compared to PPSRC emphasizing a need to develop a proper guideline in selection of the test method.

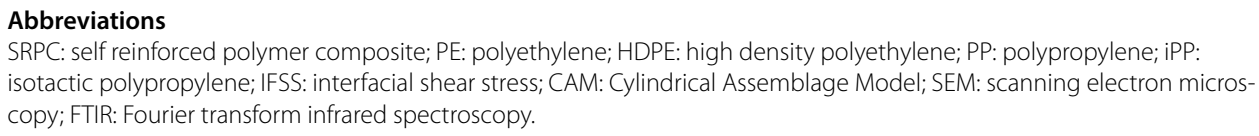

Acknowledgements

The CAMPT laboratories, VIT-University, Vellore, and M. Ramya are gratefully acknowledged for their assistance and support.

\section{Authors' contributions}

MSC performed the fabrication, testing and analysis of the data. Was guided by KP in the role of a Ph.D. supervisor, performed Fractography and helped in interpreting the data. MSC prepared the initial draft of the paper and KP corrected and added additional information required for the discussion. Both authors read and approved the final manuscript.

Funding

From School fund for research activities, VIT University, Vellore, Tamil nadu, India-632014.

Availability of data and materials

The datasets used and/or analysed during the current study are available from the corresponding author on reasonable request.

Competing interests

The authors declare that they have no competing interests.

\section{Author details}

${ }^{1}$ Department of Design and Automation, School of Mechanical Engineering, Vellore Institute of Technology, Vellore, Tamil Nadu 632014, India. ${ }^{2}$ Department of Manufacturing Engineering, School of Mechanical Engineering, Vellore Institute of Technology University, Vellore, Tamil Nadu 632014, India.

Received: 20 June 2019 Accepted: 12 September 2019

Published online: 23 September 2019

\section{References}

1. Shiriajeva GV, Andreevskaya GD. Method of determination of the adhesion of resins to the surface of glass fibers. Plast Massy (Polym Compd USSR). 1962:4:42-3. 
2. Penn LS, Bowler ER. A new approach to surface energy characterization for adhesive performance prediction. Surf Interface Anal. 1981;3:161-4.

3. Désarmot G, Avre JP. Advances in pull-out testing and data analysis. Compos Sci Technol. 1991;42:151-87.

4. Miller $B$, Muri $P$, Rebenfeld $L$. A microbond method for determination of the shear strength of a fiber-resin interface. Compos Sci Technol. 1987;28:17-32.

5. Day RJ, Cauich-Rodrigez JV. Investigation of the micromechanics of the microbond test. Compos Sci Technol. 1998;58:907-14.

6. Zhandarov SF, Pisanova EV. The local bond strength and its determination by the fragmentation and pull-out tests. Compos Sci Technol. 1997;57:957-64.

7. Jacobasch HJ, Grundke K, Uhlmann P, Simon F, Mäder E. Comparison of surface-chemical methods for characterizing carbon fiber-epoxy resin composites. Compos Interfaces. 1996:3:293-320.

8. Gorbatkina YA. Adhesive strength of fiber-polymer systems. New York: Ellis Horwood; 1992.

9. Zhandarov S, Pisanova E, Schneider K. Fiber-stretching test: a new technique for characterizing the fiber-matrix interface using direct observation of crack initiation and propagation. J Adhes Sci Technol. 2000;14:381-98.

10. Graupner N, Rößler J, Ziegmann G, Müssig J. Fibre/matrix adhesion of cellulose fibres in PLA, PP and MAPP: a critical review of pull-out test, microbond test and single fibre fragmentation test results. Compos A Appl Sci Manuf. 2014;63:133-48.

11. Zhandarov S, Mäder E. An alternative method of determining the local interfacial shear strength from force-displacement curves in the pull-out and microbond tests. Int J Adhes Adhes. 2014;55:37-42.

12. Zhuang $X$, Yan $X$. Investigation of damage mechanisms in self-reinforced polyethylene composites by acoustic emission. Compos Sci Technol. 2006;66(3-4):444-9.

13. Capiati NJ, Porter RS. The concept of one polymer composites modelled with high density polyethylene. J Mater Sci. 1975;10:1671-7.

14. Zhi C, Long H, Miao M. Microbond testing and finite element simulation of fibre-microballoon-epoxy ternary composites. Polym Test. 2018;65(2017):450-8.

15. Ma Y, et al. Enhanced interfacial properties of carbon fiber reinforced polyamide 6 composites by grafting graphene oxide onto fiber surface. Appl Surf Sci. 2018;452:286-98.

16. Wang Z, Xian G, Zhao XL. Effects of hydrothermal aging on carbon fibre/epoxy composites with different interfacial bonding strength. Constr Build Mater. 2018;161:634-48.

17. Minty RF, Yang L, Thomason JL. The influence of hardener-to-epoxy ratio on the interfacial strength in glass fibre reinforced epoxy composites. Compos A Appl Sci Manuf. 2018;112(2017):64-70.

18. Seghini MC, Touchard F, Sarasini F, Chocinski-Arnault L, Mellier D, Tirillò J. Interfacial adhesion assessment in flax/epoxy and in flax/vinylester composites by single yarn fragmentation test: correlation with micro-CT analysis. Compos A Appl Sci Manuf. 2018;113:66-75.

19. Fu J, et al. Enhancing interfacial properties of carbon fibers reinforced epoxy composites via Layer-by-Layer self assembly GO/SiO 2 multilayers films on carbon fibers surface. Appl Surf Sci. 2019;470(2018):543-54.

20. Réquilé S, Le Duigou A, Bourmaud A, Baley C. Interfacial properties of hemp fiber/epoxy system measured by microdroplet test: effect of relative humidity. Compos Sci Technol. 2019;181:107694.

21. Chandran SM, Padmanabhan K, Maxime Zilliox CKT. Processing and mechanical characterization of self reinforced polymer composite systems. Int J Chem Tech Res. 2014; 6:3310-3313.

22. Kim JK, Yiu-Wing MY. A novel microbond bundle pullout technique to evaluate the interfacial properties of fibre-reinforced plastic composites. In: Engineered interfaces in fiber reinforced composites. Chapter 3. Amsterdam: Elsevier. 1998 p. 43-52.

23. Sastry AM, Phoenix SL, Schwartz P. Analysis of interfacial failure in a composite microbundle pull-out experiment. Compos Sci Technol. 1993;48:237.

24. Padmanabhan K. Bull Mater Sci. 2017:40:737-44.

25. Padmanabhan K, Yue CY. In: Proc-ACUN-4, UNSW, Sydney, Australia, July 21-25, 2002.

26. Padmanabhan K. In: Innovative manufacturing systems and technology, a report to the Singapore-MIT Alliance, NTU, Singapore, November 2002.

27. Barbero EJ. Chapter 4. Introduction to composite materials design. Taylor and Francis. 1999. p. 91-9.

28. Miller B, Gaur U. Microbond method for determination of the shear strength of a fiber/resin interface: Evaluation of experimental parameters. Compos Sci Technol. 1989;34:35-51.

29. Miller B, Gaur U, Hirt DE. Measurement and mechanical aspects of the microbond pull-out technique for obtaining fiber/resin interfacial shear strength. Compos Sci Technol. 1991;42(1-3):207-19.

30. Piggott MR. A new model for interface failure in fibre-reinforced polymers. Compos Sci Technol. 1995;55(3):269-276

31. Hirabayashi $\mathrm{M}$, et al. Investigation of interface bonding mechanisms between glassy carbon microelectrodes and polyimide substrate through Fourier transform infrared spectroscopy. J Electrochem Soc. 2018;165(8):B3060-70.

32. Bhargava R, Wang S-Q, Koenig JL. FTIR microspectroscopy of polymeric systems. 2012. p. 137-91.

33. Lee CH, Wu TL, Chen YL, Wu JH. Characteristics and discrimination of five types of wood-plastic composites by FTIR spectroscopy combined with principal component analysis. Holzforschung. 2010;64(6):699-704.

34. Bokobza L. Spectroscopic techniques for the characterization of polymer nanocomposites: a review. Polymers. 2017;10(1):7.

35. Nishikawa M, Okabe T, Hemmi K, Takeda N. Micromechanical modeling of the microbond test to quantify the interfacial properties of fibre-reinforced composites. Int J Solid Struct. 2008;45:4098-113.

\section{Publisher's Note}

Springer Nature remains neutral with regard to jurisdictional claims in published maps and institutional affliations. 